\title{
Sequential microbial-photocatalytic degradation of imidacloprid
}

\author{
Teena Sharma', Manpreet Kaur', Amit Sobti ${ }^{3}$, Anita Rajor ${ }^{1}$, Amrit Pal Toor ${ }^{2,3^{+}}$ \\ ${ }^{1}$ School of Energy and Environment, Thapar Institute of Engineering and Technology, Patiala-147004, Punjab, India \\ ${ }^{2}$ Energy Research Centre, Panjab University, Chandigarh-160014, India \\ ${ }^{3}$ Dr. SSB University Institute of Chemical Engineering \& Technology, Panjab University, Chandigarh- 160014, India
}

\section{ABSTRACT}

In the present study, the application of sequential biological and photocatalytic process was evaluated as a feasible process for the degradation of imidacloprid (IMI) in soil. Photocatalysis was carried out as a post and pre-treatment to the biological process as Microbial Photocatalytic (MP) and Photocatalytic Microbial (PM), respectively, to enhance the degradation and mineralization of IMI in soil. By both the processes, there was an enhancement in the percentage degradation of IMI i.e $86.2 \%$ for PM and $94.6 \%$ for MP process. The obtained results indicate that MP process is apparently more efficient in degradation of IMI which was observed with 15 days of biological treatment followed by 18 $\mathrm{h}$ of photocatalytic degradation $(15 \mathrm{~d}+18 \mathrm{~h})$. The present work also reveals that though the difference in terms of the degradation of IMI after $5 \mathrm{~d}+18 \mathrm{~h}, 10 \mathrm{~d}+18 \mathrm{~h} \& 15 \mathrm{~d}+18 \mathrm{~h}$ of MP process is not drastic, yet significant variation has been observed in terms of mineralization that truly signifies the removal of IMI from the soil. The LC analysis has shown that the intermediates formed during MP process are more and smaller in comparison to PM process, which further provides evidence that MP process is better than PM process for effective degradation of IMI in soil.

Keywords: Imidacloprid, Microbial degradation, Photocatalytic degradation, Sequential degradation, Soil

\section{Introduction}

Imidacloprid (IMI) is an extensively used insecticide on many food crops, turf and flea control. IMI is broad spectrum, nicotine based insecticide, which has been widely used to control the various insects namely aphids, thrips, whiteflies etc. on a broad range of crops. Excessive use of IMI will lead to extensive environmental pollution which has high risk to human health. Over the past several decades, continuous utilization of imidacloprid has resulted in the accumulation of this compound in soil, therefore making it hazardous for the environment [1-2]. In the environment, the IMI is highly toxic to non-target organisms including birds, bees, soil microbes and aquatic animals [3-4]. In addition, IMI can be taken up by crops and thus enter the food chain which may ultimately harm humans and terrestrial vertebrates [5]. Therefore, development of an efficient and eco-friendly approach to remediate IMI contaminated soil is the need of an h.

Various methods have been studied for the degradation of IMI in water such as photocatalytic degradation [6-7], pho- to-fenton [8-9], ozonation [10], adsorption [11], photolytic [12-13] and fenton-like catalytic oxidation [14], however, only few studies on the degradation of IMI in soil have been reported [15-22]. Photocatalytic degradation and biodegradation have been reported to be the major degradation processes of IMI residues. In fact, the studies reported for the degradation of IMI in soil using photocatalytic degradation are scarce. Sharma et al. [15] have reported the photocatalytic degradation of IMI in soil using $\mathrm{TiO}_{2}$ as a photocatalyst. The authors have maximized the degradation of IMI by optimizing the various parameters using central composite design based on response surface methodology supported by Design Expert software. As high as 83\% degradation of IMI in soil was achieved under optimized conditions. Different studies revealed that imidacloprid can be removed by natural process in natural environment using microbes. Various research groups have reported microbial degradation of IMI in soil using various strains such as Enterobacter sp. strain ATA1 [16], Bacillus aerophilus [17], Ochrobactrum sp. BCL1 [18], Klebsiella Pneumoniae strain BCH1 [19], Bacillus weihenstephanensis [20], Burkholderia cepacia. strain CH9 [21] and Liefsonia strain PC21
This is an Open Access article distributed under the terms of the Creative Commons Attribution Non-Commercial License (http://creativecommons.org/licenses/by-nc/3.0/) which permits unrestricted non-commercial use, distribution, and reproduction in any medium, provided the original work is properly cited.

Copyright (C) 2020 Korean Society of Environmental Engineers
Received April 15, 2019 Accepted August 23, 2019

${ }^{\dagger}$ Corresponding author

Email: aptoor@yahoo.com

Tel: +0172-253-4904

ORCID: 0000-0002-7092-1548 
[22]. As compared to traditional chemical treatment method, biological remediation is much cheaper and eco-friendly. But they are more selective and sensitive to process parameters such as contamination or toxicity [23-26]. Combination of high activity of photo-chemical treatment and cost efficiency of biological treatment could result in maximum mineralisation of pollutant. This coupling process should be focused to convert parent molecules to non-toxic intermediates using photocatalytic degradation, which could further be removed completely by biological processes [27-30]. The combined biological and photocatalytic treatment in a sequential manner is a process where photocatalytic method is used as pre or post treatment to biological method.

The use of photodegradation process as a pre-treatment to biological process has been reported by a few researchers. Essam et al. [31, 32] \& Tamer et al. [33] have studied the sequential degradation of mixture of chlorophenols in water. The authors have reported that only UV treatment is not satisfactory for pollutant degradation, however, the highest de-chlorination efficiency and highest pollutant degradation rates were supported by sequential treatment. Therefore, they applied a combination of both photochemical-biological treatment through which mineralisation of chlorophenols was achieved economically and effectively.

To the best of our knowledge the work concerning sequential degradation of pesticides in soil relevant to IMI is hard to find in the literature. Not much work has been reported on sequential degradation (pre and post photocatalytic treatment to microbial process) of organic compounds and specifically on sequential degradation of pesticides in soil as well as in water, however, few studies on sequential degradation of some dyes have been reported which have shown that the sequential process could be an efficient process compared to individual photocatalytic or biological treatment, e.g. Degradation and decolorization of Reactive Black 5 azodye through combined biological and photocatalytic processes has been reported by Shah [34]. The results showed that using biological treatment the aromatic rings did not degraded, however, using biological treatment followed by photocatalytic treatment the absorbance peak significantly disappears in the UV region after $2 \mathrm{~h}$ of illumination. Samir et al. [35] also suggested the use of combined process as it is more effective than the individual biological or photocatalytic treatment. He examined that the pre-treatment of 2, 4-Dichlorophenoxy acetic acid $(2,4-\mathrm{D})$ with UV radiation in presence of photocatalyst $\left(\mathrm{TiO}_{2}\right)$ accelerated the biodegradation process.

With this perspective, IMI degradation by sequential biological-photocatalytic treatment using $\mathrm{TiO}_{2}$ nanoparticles as a photocatalyst and IMI degrading isolated bacteria was investigated. In our previous work, the individual biological and photocatalytic degradation of IMI in soil was achieved [15, 16], however, not much has been reported on sequential degradation for remediation of IMI in soil. Therefore, degradation of IMI in sequential manner as microbial-photocatalytic and photocatalytic- microbial was studied for maximum possible mineralization of IMI.

\section{Materials and Methods}

Technical grade Imidacloprid (purity 99\%) and $\mathrm{TiO}_{2}$ (Degussa P25) having an average particle size of $30-50 \mathrm{~nm}$ with an anatase to rutile ratio of 80:20 were obtained as gift sample from Bayer crop science India Ltd., Mumbai and Evonik Industries, respectively [15]. Deionized water, $\mathrm{H}_{2} \mathrm{SO}_{4}$ and $\mathrm{NaOH}$ were obtained from Loba Chemi, India. HPLC grade solvents (acetonitrile, methanol) were used in the experimental work and are purchased from Merck. For the preparation of minimal media, all the other chemicals used were of high analytical grade. For the growth of Enterobactor $s p$. strain ATA1 the minimal media used was same as given in our previous studies [16, 36].

\subsection{Experimental Procedure}

Soil, with no history of pesticide, was collected from Thapar University campus, Patiala, Punjab, India. The physicochemical characteristics of soil which was dried, homogenized and sterilized prior to the experiments were determined in accordance to standard methods [37]. Initially, the soil samples were air dried and were made to pass through a sieve of $1 \mathrm{~mm}$, which were then autoclaved $\left(121^{\circ} \mathrm{C}, 3 \times 30 \mathrm{~min}\right)$ and finally stored in dark. The experiments for IMI degradation were carried out at a soil $\mathrm{pH}$ of 7 , which was considered to be an optimum value as determined in our previous studies [16, 37] and at ambient temperature.

\subsubsection{Photocatalytic degradation}

UV reactor equipped with $6 \mathrm{UV}$ lamps (Phillips, $20 \mathrm{~W}$ ) was used to study the photodegradation process using $\mathrm{TiO}_{2}$ as photocatalyst. Further, the arrangements were made in such a manner that the height of the soil samples can be varied with respect to the UV light. An exhaust fan was used to maintain the internal temperature of the chamber. $\mathrm{HCl} / \mathrm{NaOH}$ solutions $(0.1 \mathrm{~N})$ were used to maintain $\mathrm{pH}$ of the soil. Water below the soil sample Petri-plates was circulated to maintain the temperature [15]. The soil samples were spiked with $50 \mathrm{mg} \mathrm{kg}^{-1}$ using an acetonitrile solution of IMI. Five gram of soil was spread uniformly on the glass Petri-plates (90 $\mathrm{mm}$ diameter), because of which a layer of $0.2 \mathrm{~cm}$ was formed which has been determined from Petri-plate area and soil bulk density.

\subsubsection{Microbial degradation}

Microcosm consists of $50 \mathrm{~g}$ soil spiked with required IMI concentration. Enterobactor sp. strain ATA1 isolated from paddy field soil at Punjab $[16,36]$ was grown in minimal media with glucose (MMG: $1 \%$ glucose $\mathrm{w} / \mathrm{v}$ ) at a temperature of $37^{\circ} \mathrm{C}$ on a rotary shaker for $30 \mathrm{~h}$ followed by induction with IMI. This was further grown for $5 \mathrm{~h}$ after which the cells were harvested by centrifugation carried out at a temperature of $4^{\circ} \mathrm{C}$ and 10,000 rpm for $10 \mathrm{~min}$ [16]. Cells were washed three times. Further, the dilution plate count technique was used to quantify the cells. Bacterial cells $\left(2 \times 10^{8}\right.$ cells $\left.\mathrm{mL}^{-1}\right)$ were added in IMI spiked soil in microcosm to conduct experiments. In different set of beakers, minimal medium (un-inoculated) was added as control. Culture were carefully mixed in soil and incubated at $37^{\circ} \mathrm{C}$ for 5, 10 and $15 \mathrm{~d}$ under sterile conditions [37]. Moist conditions were maintained by spraying approximately $3 \mathrm{~mL}$ of sterile distilled water after every three days. Approximately $2 \mathrm{~g}$ of soil sample was removed at different time intervals which were then analyzed for imidacloprid concentration. 


\section{Analysis}

The growth of isolates and degradation of IMI in soil was analysed using UV-Vis spectrophotometer (model: HITACHI U-2800, Japan). Various metabolites formed during IMI degradation were determined qualitatively using Liquid Chromatography. HPLC (Agient LC 1120) technique in reverse phase, using C-18 columns (BDS, Qualigens) at ambient temperature, was used to analyse the reaction solution obtained after IMI degradation.

\section{Results and Discussion}

The individual photocatalytic degradation and microbial degradation using ATA1 has been reported in our previous studies [15-16]. In the present work the sequential photocatalytic and microbial degradation was studied by photocatalytic degradation as pre or post treatment to microbial degradation i.e. photocatalytic degradation of IMI followed by the microbial treatment (PM) and microbial followed by photocatalytic degradation (MP).

\subsection{Photocatalytic-Microbial (PM) Degradation}

In this process (Fig. 1(a), (b)), soil was pre-treated photo-catalytically prior to the microbial degradation of IMI. The photocatalytic degradation was studied at optimised condition of $0.3 \mathrm{~g} \mathrm{TiO}_{2}$ per $\mathrm{kg}$
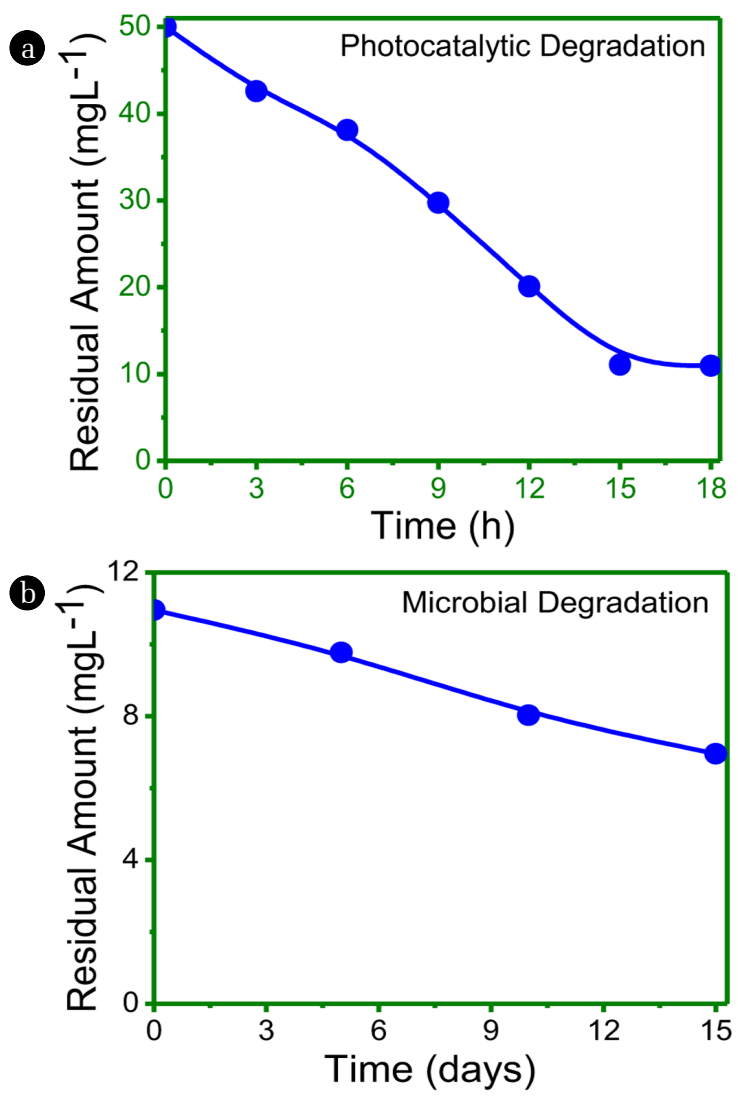

Fig. 1. Sequential process for degradation of IMI in soil by: (a) Photocatalytic degradation followed by (b) Microbial degradation.

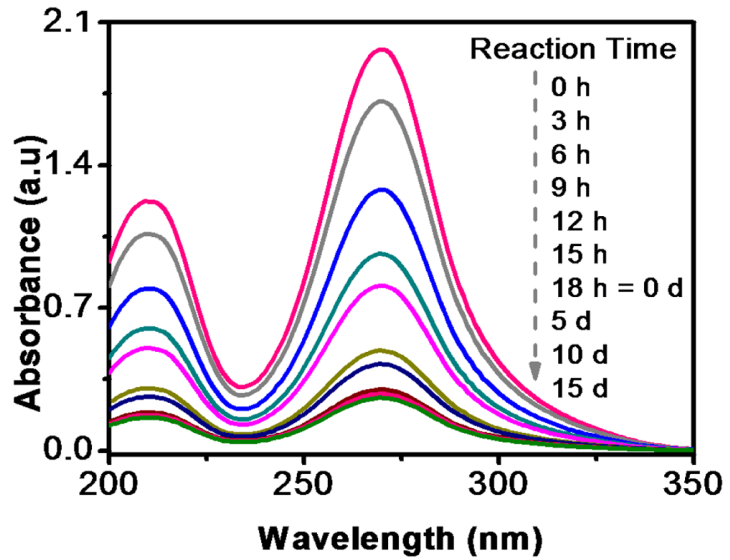

Fig. 2. Time course UV spectra of $\mathrm{IMI}\left(50 \mathrm{mg} \mathrm{L}^{-1}\right)$ during photocatlytic-microbial- process.

as reported earlier [15]. The photo-catalytically treated soil was further treated with strain Enterobactor sp. strain ATA1 under the optimised conditions of $\mathrm{pH}-7$ and $1 \%$ glucose at $37^{\circ} \mathrm{C}$ [16] for microbial degradation and continued for $15 \mathrm{~d}$.

It was observed from Fig. 1(a), that the initial decrease in residual amount of IMI (50 ppm) occurred up to $18 \mathrm{~h}$ of photo-catalytic degradation which shows that the residual amount of IMI after photocatalytic degradation was found to be $78 \%$ degraded. This was further treated by microbial process for 15 days, which further lead to $86.2 \%$ degradation.

Fig. 2 shows the time course study of UV-Vis absorption spectra for IMI degradation in soil during PM process. It is observed from Fig. 2 that the peak corresponding to $\lambda_{\max }=270$ decreased gradually with increase in time of degradation. A significant decrease in peak height compared to standard IMI was observed during $18 \mathrm{~h}$ of irradiation and further degradation was comparatively slow after $5 \mathrm{~d}$ of biological treatment, which shows that IMI intermediate formed after photocatalytic degradation might be toxic to strain ATA1. Hence, there is a decrease in the biological degradation.

\subsection{Microbial-Photocatalytic (MP) Process}

In this process, microbial degradation of IMI was followed by its photocatalytic treatment. The microbial degradation of IMI (50 ppm) was attained using bacterial strain ATAI for 15 days. Further, the obtained sample, after microbial degradation, was additionally irradiated for $18 \mathrm{~h}$ for photo-catalytic degradation under optimized conditions as explained above. It is observed from Fig. 3(a) that IMI shows 55.6\% degradation after $10 \mathrm{~d}$ of incubation and further degraded to $58.2 \%$ after $15 \mathrm{~d}$. Afterwards, a significant degradation was observed upto 94.6\% after $18 \mathrm{~h}$ of irradiation under optimised photocatalytic condition (Fig. 3(b)).

Fig. 4 represents the UV-Vis. spectra for MP process which indicates a decrease in peak height compared to standard IMI after $5 \mathrm{~d}$ that became almost constant till 15th $\mathrm{d}$ of incubation. Thereafter, the photo-catalytic degradation carried out after microbial treatment caused further decrease in peak height. 

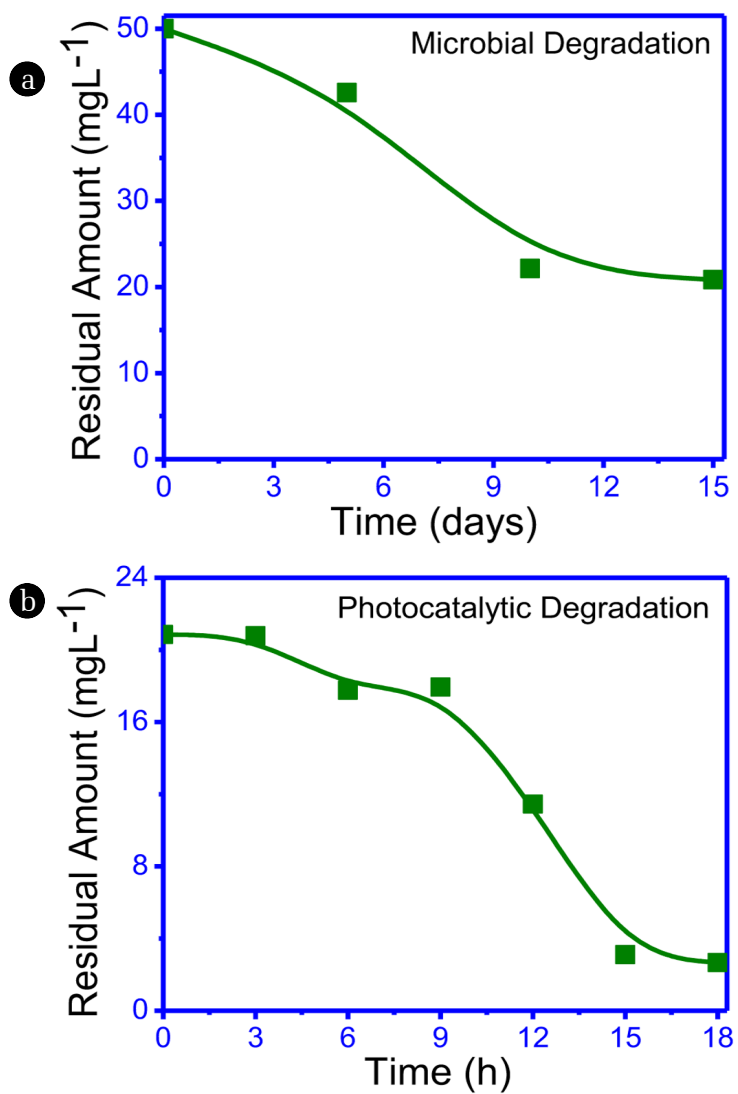

Fig. 3. Sequential process for degradation of IMI in soil by: (a) Microbial degradation followed by (b) Photocatalytic degradation.

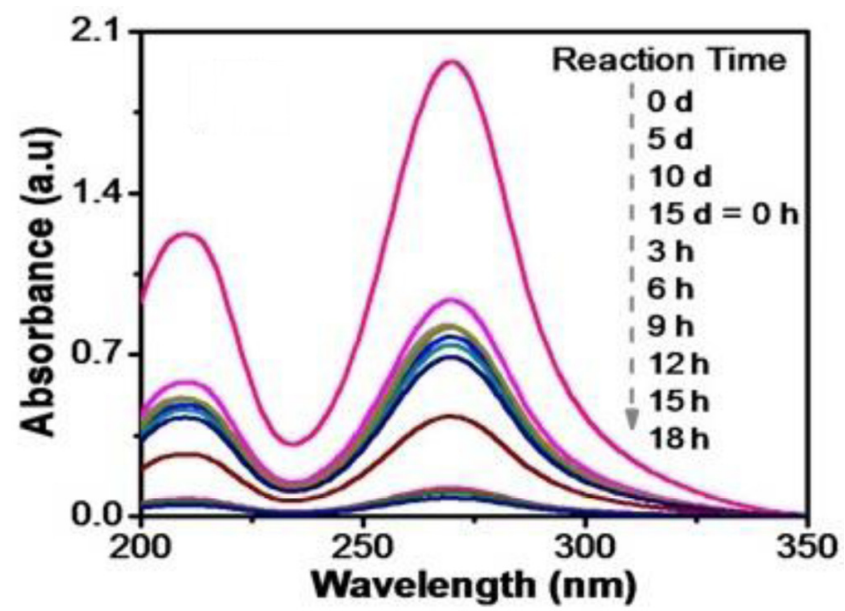

Fig. 4. Time course UV spectra of IMI (50 mg L-1) during Microbial-photocatlytic process.

\subsection{Comparison of Microbial-photocatalytic (MP) and Photocatalytic-Microbial (PM) Processes}

In this study, the comparison of both the processes $(18 \mathrm{~h}+15$ $\mathrm{d}$ for PM process and $15 \mathrm{~d}+18 \mathrm{~h}$ for MP process) was done in terms of degradation and mineralization. On comparing both the processes in terms of residual amount of IMI it was concluded that MP process (94.6\% degradation) is better than PM process (86.2\% degradation). This comparatively high activity of MP process can be explained on the fact that during the PM process, degradation of IMI by photo-degradation could have led to the formation of some intermediates which might be toxic to the strain ATA1, resulting a decrease in the enzymatic activity of microbes. To further know about the intermediates formed after $18 \mathrm{~h}$ of photocatalytic degradation, Mass-Spectrum analysis was carried out and is represented in Fig. S1 in supplementary sheet. From Fig. S1, it is observed that the smaller molecule intermediates such as pent-2-ene-1-amine (m/z 84; RT 3.32) and 2-chloro-5-methylene pyridine (m/z 128; RT 1.63) are formed which might be toxic to strain ATA1 [37]. The similar findings were also reported earlier by Jafari et al. [38] \& Gonzalez et al. [39], showing reduction in activity of PM process for azo dye and chlorophenols degradation, respectively. Higher concentration of IMI might be the another reason which did not favour the photocatalytic process as pre-treatment for degradation and the same was emphasized in other studies [40-42] as well. It is observed from the present findings that, though the difference in degradation efficiency among the two processes is very small, yet is found to be very significant which has been supported by LC analysis shown in Fig. 5(a), (b). It is observed from Fig. 5(a) and Fig. 5(b) that the number of intermediates formed during the MP process is more as compared to PM process. Further, among the identified intermediates, two intermediates viz. I-1 (2-chloro-5-methylpyridine) and I-2 (4-hydroxy-imidacloprid urea) shown in Fig. 5(c) are commonly formed during both of the studied processes [37].

More number of intermediates formed during the MP process gives evidence that MP process could be better than PM process. Therefore, to further confirm this, time course study of the commonly formed intermediates was also carried out. The results were interpreted in terms of ratio of peak area at any time $t$ (Area ${ }_{(\mathrm{t})}$ ) to the maximum of peak area (Area ${ }_{(\max )}$ ) as a function of time and are given in Fig. 6. It is observed from Fig. 6(a) that in MP process the amount of common intermediates maximized after about initial $5 \mathrm{~d}$ and thereafter the growth of these intermediates is almost constant until $15 \mathrm{~d}$ of biological treatment. Further, when the photocatalytic process is applied after $15 \mathrm{~d}$ of biological treatment, the drastic degradation of these intermediates is observed.

However, in case of PM process (Fig. 6(b)) the formation of these intermediates continued until the maximum time $(18 \mathrm{~h}+$ $15 \mathrm{~d})$ and were not broken by bacteria ATA1 because the carbon source utilized by bacteria was become very negligible and ATA1 was unable to utilize these intermediates for its growth purpose, therefore, due to the lack of carbon source further breakdown of intermediates was stopped (Fig. 6(b)). Moreover, these intermediates might be toxic for strain ATA1.

This shows that the degradation of these intermediates is possible with photocatalytic process applied after $15 \mathrm{~d}$ of biological treatment whereas biological treatment given after $18 \mathrm{~h}$ of photocatalytic process has not been able to break these intermediates further. This is also in accordance with our initial studies [15, 36], where it was observed that with only $15 \mathrm{~d}$ of biological process the intermediates formed were imidacloprid urea, imidacloprid guanidine, 2-iminoimidazolidine-4, 5-diol and 1-methyl imidazolidine-2-imine [36], where as in case of photocatalytic process these intermediates 

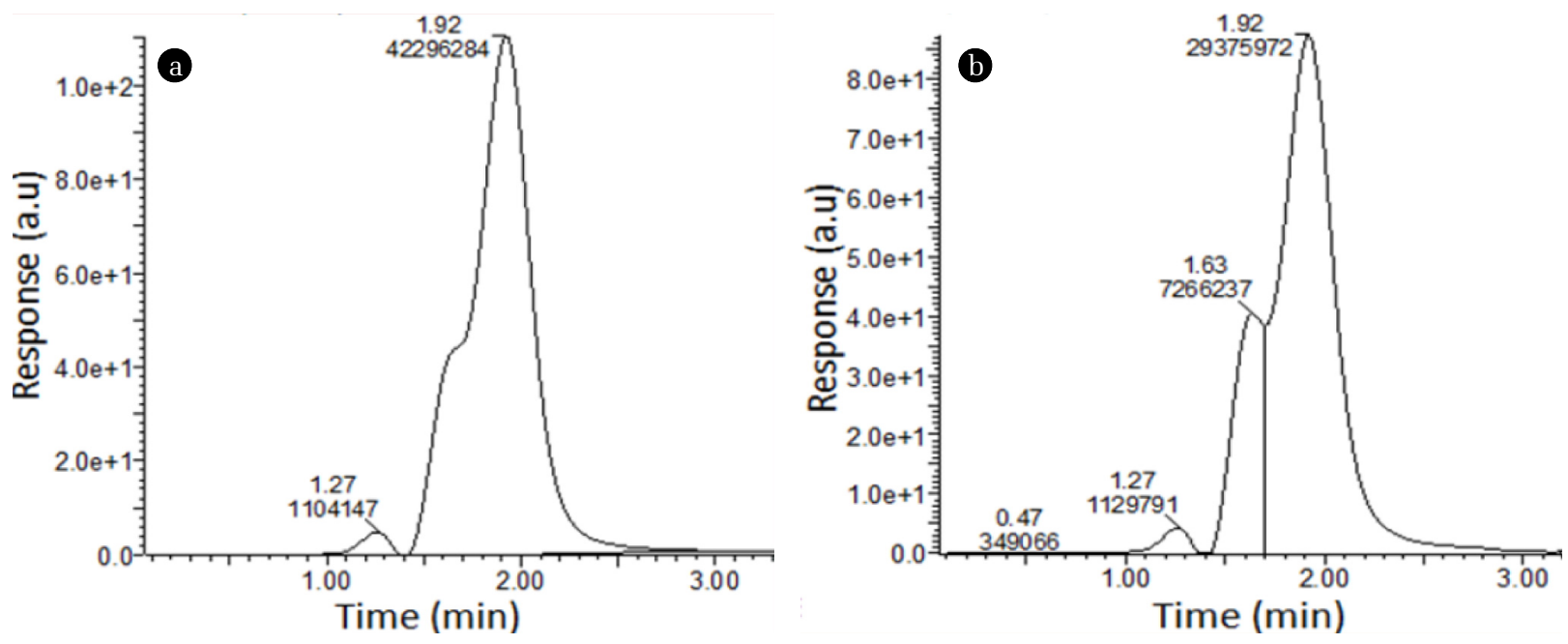<smiles>Cc1ccc(Cl)nc1</smiles>

$(\mathrm{I}-1)$<smiles>CCCCCCCCCCCO</smiles>

$(1-2)$

Fig. 5. LC analysis for Sequential degradation of IMI (50 mg kg-1) (a) Photocatalytic-biological degradation at $18 \mathrm{~h}+15 \mathrm{~d}$ time interval (b) Biological-photocatalytic degradation at $15 \mathrm{~d}+18 \mathrm{~h}$ time interval. (c) Common identified intermediates of IMI produced by MP and PM processes.
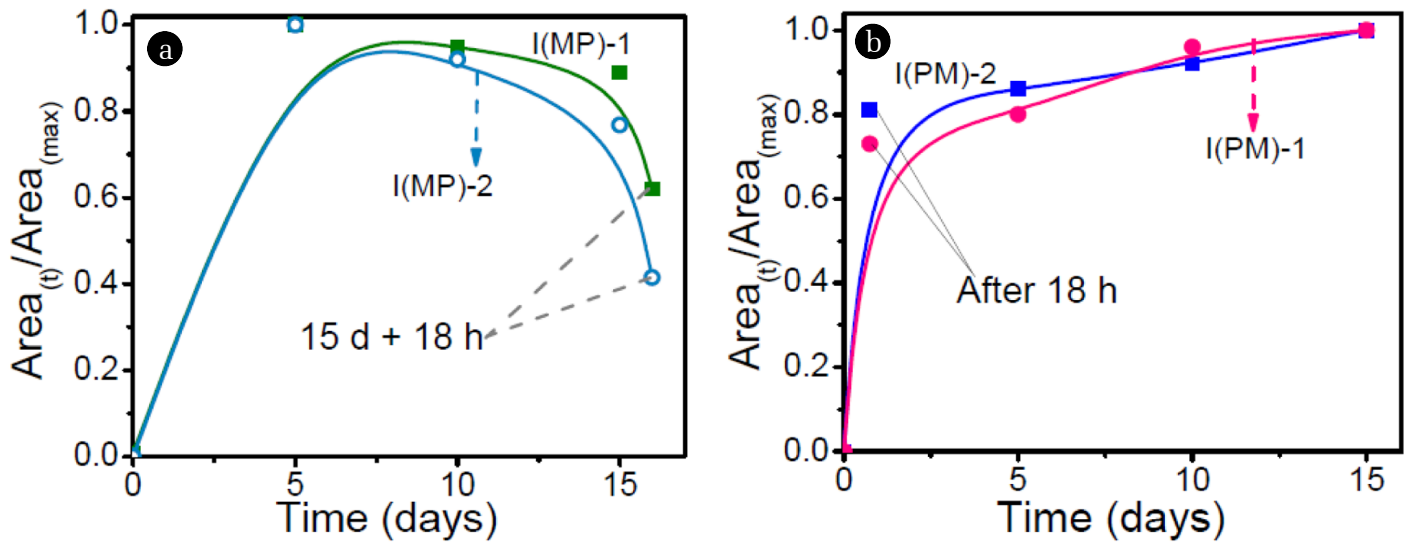

Fig. 6. Time course sequential degradation of IMI (50 mg kg-1) (a) Microbial followed by Photocatalytic degradation (MP) (b) Photocatalytic followed by Microbial degradation (PM).

have been broken into smaller molecules such as pent-2-ene1-amine and 2-chloro-5-methylpyridine [15]. The results clearly depict that in spite of insignificant increase in amount of IMI degradation during the MP process, drastic change in-terms of number of intermediates produced and eventually their mineralization is observed confirming the superiority of MP process compared to PM process.

\subsubsection{Kinetic study}

Langmuir-Hinshelwood (L-H) model is widely used to represent the degradation kinetics of many organic pollutants, which can be expressed as:

$$
-\frac{d C}{d t}=\frac{k_{r} K C_{o}}{\left(1+K C_{o}\right)}
$$


where $d C / d t$ ( $\mathrm{mg} \mathrm{L}^{-1} \mathrm{~min}^{-1}$ ) is the rate of degradation; $C\left(\mathrm{mg} \mathrm{L}^{-1}\right)$ is the concentration at any time $t ; C_{\mathrm{o}}\left(\mathrm{mg} \mathrm{L}^{-1}\right)$ is the initial concentration; $K$ is the equilibrium adsorption constant; $k_{\mathrm{r}}$ is the reaction rate constant. For low initial substrate concentration, $(K<<<1$, and hence neglected) Eq. (1) reduces to apparent 1st order kinetics, expressed as [43]:

$$
\ln \left(\frac{C_{o}}{C}\right)=k_{r} K t=k_{a p p} t
$$

where $k_{\text {app }}$ is the apparent rate constant $\left(\mathrm{min}^{-1}\right)$, which can be determined by plotting $-\ln C / C_{o}$ as a function of irradiation time.

The data for photocatalytic degradation for pre and post treatment to the biological process are represented in supplementary Fig. S2. The apparent rate constants, as determined from the slope of a straight line obtained by plotting $-\ln C / C_{o}$ as a function of irradiation time, are $0.082 \mathrm{~min}^{-1}$ and $0.126 \mathrm{~min}^{-1}$ with a regression coefficient of 0.98 and 0.95 , respectively, for pre and post photocatalytic treatment to the biological process. Higher value of apparent rate constant in case of post photocatalytic treatment to the biological process clearly indicates that following a post photocatalytic treatment to the biological process (MP process) is a better option compared to pre-treatment followed by biological process (PM process). This further supports the discussion given in section 4.3 .

\subsection{Comparison of Degradation and Mineralization $\left(5^{\text {th }}\right.$ and $10^{\text {th }} \mathrm{d}$ ) in Microbial-Photocatalytic Process}

As observed from Fig 4, in MP process the degradation of IMI observed after $5 \mathrm{~d}$ of biological degradation process was found to be of not much difference compared to $10 \mathrm{~d}$ or $15 \mathrm{~d}$ of biological treatment. Therefore, it is observed that better or same results could be obtained with photocatalytic process applied on $5^{\text {th }}$ and $10^{\text {th }}$ day of biological degradation rather than photocatalytic process applied on $15^{\text {th }}$ day of biological process. Therefore, to verify this, the samples obtained after $5 \mathrm{~d}$ and $10 \mathrm{~d}$ of biological degradation were subjected to $18 \mathrm{~h}$ of photocatalytic degradation of IMI and the results thus obtained are shown in Fig. 7 along with the MP process for $15 \mathrm{~d}+18 \mathrm{~h}$.

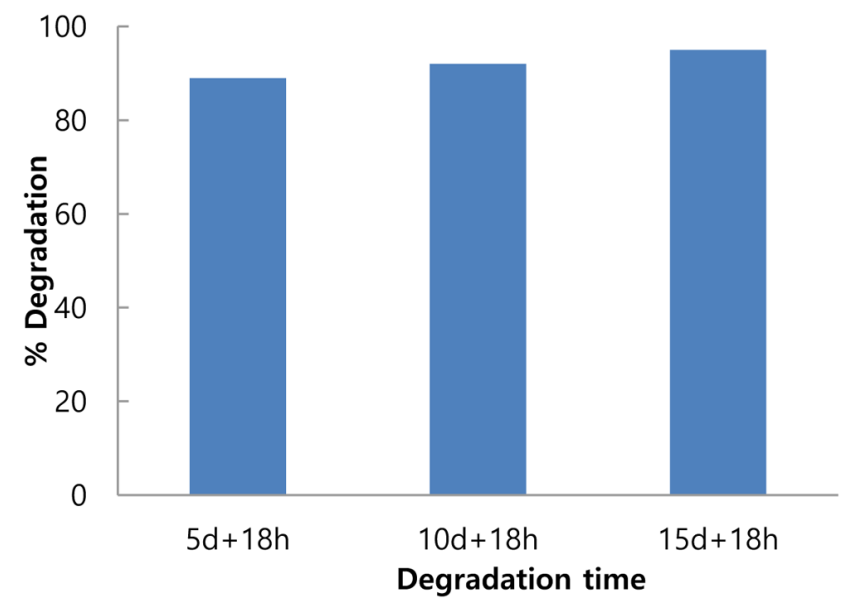

Fig. 7. Degradation of IMI at various time interval of MP process.
It is observed from Fig. 7 that the microbial-photocatalytic degradation of IMI in soil obtained after $5 \mathrm{~d}+18 \mathrm{~h}, 10 \mathrm{~d}+18 \mathrm{~h}$ and $15 \mathrm{~d}+18 \mathrm{~h}$ is $89 \%, 92 \%$ and $95 \%$, respectively, which shows that there is not much difference in the final degradation of IMI after $5 \mathrm{~d}+18 \mathrm{~h}, 10 \mathrm{~d}+18 \mathrm{~h}$ and $15 \mathrm{~d}+18 \mathrm{~h}$ of MP process. These results also suggest that the process of photocatalytic degradation of IMI in soil could be applied after $5^{\text {th }}$ day of microbial degradation. However, the samples after $5 \mathrm{~d}+18 \mathrm{~h}$ and $10 \mathrm{~d}$ $+18 \mathrm{~h}$ of microbial-photocatalytic degradation were further analysed using LC technique to check for the mineralisation, the obtained results for which are shown in Fig. 8(a) and (b).

It is observed from Fig. 8(a), (b) that only one intermediate i.e. 2-iminoimidazolidine-4, 5 -diol is formed after $5 \mathrm{~d}+18 \mathrm{~h}$ of MP process, whereas two intermediates viz. 2-iminoimidazolidine-4, 5-diol and 4-hydroxy-imidacloprid urea are formed in case of $10 \mathrm{~d}+18 \mathrm{~h}$ of MP process. These results were further compared with the results of $15 \mathrm{~d}+18 \mathrm{~h}$ of MP process as well as with our previously reported results [36] carried out using $15 \mathrm{~d}$ of biological treatment only. It is observed that 2-iminoimidazolidine-4, 5-diol intermediate which is formed after $5 \mathrm{~d}+18 \mathrm{~h}$ as well as 10 $\mathrm{d}+18 \mathrm{~h}$ of MP process was also formed after $15 \mathrm{~d}$ of biological treatment only [36], whereas this intermediate has been broken into smaller molecules if $18 \mathrm{~h}$ of photocatalytic process was followed after $15 \mathrm{~d}$ of biological treatment. This indicates that the later process $(15 \mathrm{~d}+18 \mathrm{~h})$ is better than earlier two processes
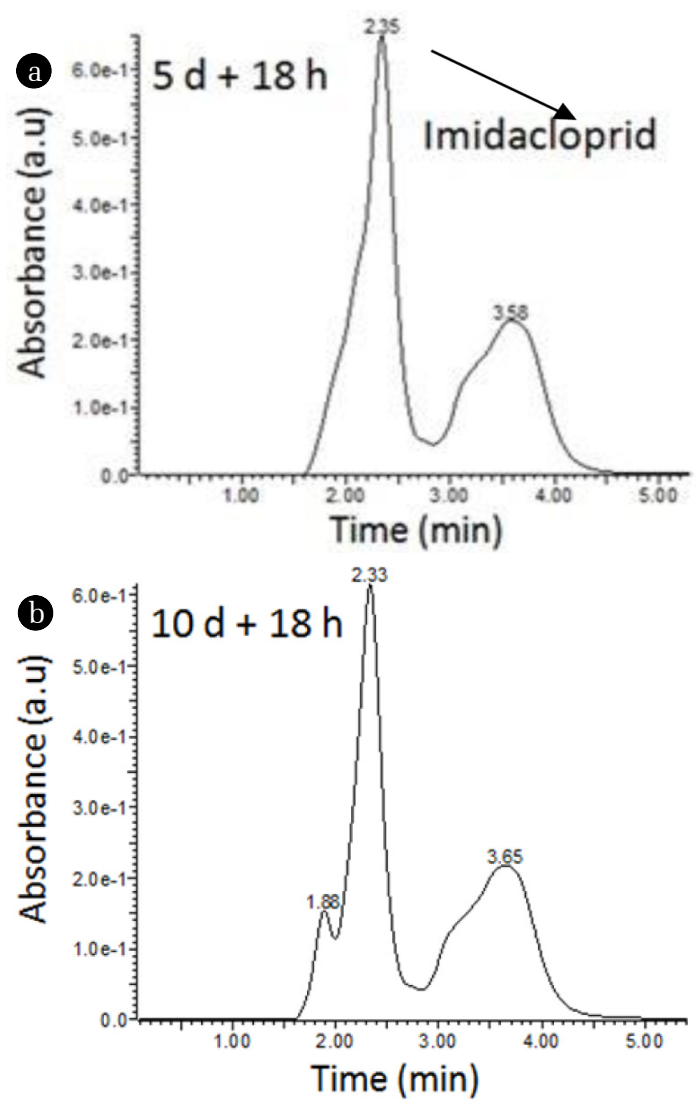

Fig. 8. LC chromatograms for degradation of IMI in MP process obtained after (a) $5 \mathrm{~d}+18 \mathrm{~h}$ (b) $10 \mathrm{~d}+18 \mathrm{~h}$. 
$(5 \mathrm{~d}+18 \mathrm{~h}$ and $10 \mathrm{~d}+18 \mathrm{~h})$. The results suggest that longer the microbial process followed by photocatalytic process $(18 \mathrm{~h})$, more efficiently it can mineralize the IMI and its intermediates. In a better way, it can be concluded that although no notable difference in terms of degradation of IMI after $5 \mathrm{~d}+18 \mathrm{~h}, 10$ $d+18 h$ and $15 d+18 h$ of MP process is observed, yet a significant variation in terms of mineralization is observed that truly signifies the removal of IMI from the soil.

\section{Conclusions}

IMI was efficiently degraded by sequential microbial and photocatalytic processes applied consecutively. Photocatalytic degradation of IMI in soil was carried out as a post and pre-treatment to the biological process as Microbial Photocatalytic process (MP) and Photocatalytic Microbial process (PM), respectively, to enhance the degradation of IMI in soil. Comparison of both the processes $(18 \mathrm{~h}+15 \mathrm{~d}$ for PM and $15 \mathrm{~d}+18 \mathrm{~h}$ for MP) was done in terms of degradation and mineralization. As high as $94.6 \%$ degradation of IMI was observed using MP process compared to $86.2 \%$ using PM process. This comparatively high activity of MP process can be explained on the fact that during the PM process, degradation of IMI by photo-degradation could have led to the formation of some intermediates which might be toxic to the strain ATA1, resulting a decrease in the enzymatic activity of microbes. Further, the LC analysis has shown that the number of intermediates formed during MP process $(15 \mathrm{~d}+18 \mathrm{~h}$ ) is more compared to PM (18 $h+15 d)$ process, which further gives evidence that MP process is better compared to PM process. Results also revealed that though there is not much difference in degradation of IMI in soil obtained after $5 \mathrm{~d}+18 \mathrm{~h}, 10 \mathrm{~d}+18 \mathrm{~h}$ and $15 \mathrm{~d}+18 \mathrm{~h}$ which is $89 \%$, $92 \%$ and $95 \%$, respectively, yet significant variation in terms of mineralization has been observed between $5 \mathrm{~d}+18 \mathrm{~h}$ and 15 $\mathrm{d}+18 \mathrm{~h}$ MP process which truly signifies the removal of IMI in soil. The results also reveal that the mineralisation was maximum for $15 \mathrm{~d}+18 \mathrm{~h}$ of MP process which shows that the removal of IMI and intermediates is maximum in this case. Based on the observed results, it is concluded that MP process is more efficient than PM process which was observed with $15 \mathrm{~d}$ of biological treatment followed by $18 \mathrm{~h}$ of photocatalytic degradation $(15 \mathrm{~d}+18 \mathrm{~h})$.

\section{References}

1. Scholz K, Spiteller M. Influence of groundcover on the degradation of 14C imidacloprid in soil, In: Proceedings, Brighton Crop protection Conference-Pests and Diseases. 23-26 November 1992; Brighton. p. 883-888.

2. Thuyet DQ, Yamazaki K, Phong TK, Watanabe H, Nhung DTT, Takagi K. Determination of imidacloprid in paddy water and soil by liquid chromatography electrospray ionization-tandem mass spectrometry. J. Anal. Chem. 2010;65:843-847.

3. Elbert A, Buchholz A, Ebbinghaus KU, Erdelen C, Nauen, R, Schnorbach HJ. The biological profile of thiacloprid-A new chloronicotinyl insecticide. Pflanzenschutz-Nachrichten Bayer 2001;54:185-208.
4. Schmuck R, Stadler T, Schmidt HW. Field relevance of a synergistic effect observed in a laboratory between an EBI fungicide and a chloronicotinyl insecticide in the honey bee (Apis mellifera L, Hymenoptera). Pest Manage. Sci. 2003;59:279-286.

5. Chopra SL, Kanwar JS. Analytical agriculture chemistry. New Delhi; Kalyani Publishers; 1991. p. 309-310.

6. Changgen F, Gang XU, Xia LIU. Photocatalytic degradation of imidacloprid by composite catalysts $\mathrm{H}_{3} \mathrm{PW}_{12} \mathrm{O}_{40} / \mathrm{La}-\mathrm{TiO}_{2}$. J. Rare. Earth 2013;31:44-48.

7. Kitsiou V, Filippidis N, Mantzavinos D, Poulios I. Heterogeneous and homogeneous photocatalytic degradation of the insecticide imidacloprid in aqueous solutions. Appl. Catal. B Environ. 2009;86:27-35.

8. Segura C, Zaror C, Mansilla HD, Mondaca MA. Imidacloprid oxidation by photo-Fenton reaction. J. Hazard. Mater. 2008;150:679-686.

9. Malato S, Caceres J, Aguera A, et al. Degradation of imidacloprid in water by photo-Fenton and $\mathrm{TiO} 2$ photocatalysis at a solar pilot plant: A comparative study. Environ. Sci. Technol. 2001;35:4359-4366

10. Chen S, Deng J, Deng Y, Gao N. Influencing factors and kinetic studies of imidacloprid degradation by ozonation. Environ. Technol. 2019;40:2127-2134.

11. Zahoor M, Mahramanlioglu M. Adsorption of imidacloprid on powdered activated carbon and magnetic activated carbon. Chem. Biochem. Eng. Q. 2011;25:55-63.

12. Redlich D, Shahin N, Ekici P, Friess A, Parlar H. Kinetical study of the photoinduced degradation of imidacloprid in aquatic media. Clean 2007;35:452-458.

13. Wamhoff H, Schneider V. Photodegradation of imidacloprid. J. Agric. Food Chem. 1999;47:1730-1734.

14. Wang YB, Zhao HY, Li MF, Fanb JA, Zhaoaet GH. Magnetic ordered mesoporous copper ferrite as a heterogeneous Fenton catalyst for the degradation of imidacloprid. Appl. Catal. B Environ. 2014;147:534-545.

15. Sharma T, Toor AP, Rajor A. Photocatalytic degradation of imidacloprid in soil: Application of response surface methodology for the optimization of parameters. RSC Adv. 2015;5: 25059-25065.

16. Sharma T, Rajor A, Toor AP. Potential of Enterobactor sp. Strain ATA1 on imidacloprid degradation in soil microcosm: Effect of various parameters. Environ. Prog. Sustain. Energy 2015;34: 1291-1297.

17. Akoijam R, Singh B. Biodegradation of imidacloprid in sandy loam soil by Bacillus aerophilus. Int. J. Environ. Anal. Chem. 2015;95:730-743.

18. Hu G, Zhao Y, Liu B, Song F, You M. Isolation of an indigenous imidacloprid-degrading bacterium and imidacloprid bioremediation under simulated in situ and ex situ conditions. J. Microbiol. Biotechnol. 2013;23:1617-1626.

19. Phugare SS, Kalyani DC, Gaikwad YB, Jadhav JP. Microbial degradation of imidacloprid and toxicological analysis of its biodegradation metabolites in silkworm (Bombyx mori). Chem. Eng. J. 2013;230:27-35.

20. Shetti AA, Kaliwal RB, Kaliwal BB. Imidacloprid induced intoxication and its biodegradation by soil isolate Bacillus weihenstephanensis. British Biotechnol. J. 2014;4:957-969. 
21. Gopal M, Dutta D, Jha SK, et al. Biodegradation of imidacloprid and metribuzin by Burkholderia cepacia strain CH9. Pestic. Res. J. 2011;23:36-40.

22. Anhalt JC, Moorman TB, Koskinen WC. Biodegradation of imidacloprid by an isolated soil microorganism. J. Environ. Sci. Health B 2007;42:509-514.

23. Amat AM, Arqus A, Beneyto H, Garacia, A, Miranda MA, Segui S. Ozonisation coupled with biological degradation for treatment of phenolic pollutants: A mechanistically based study. Chemosphere 2003;53:79-86.

24. Choi Y, Koo MS, Bokare AD, Kim D, Bahnemann DW, Choi W. Sequential process combination of photocatalytic oxidation and dark reduction for the removal of organic pollutants and $\mathrm{Cr}(\mathrm{VI})$ using Ag/ $\mathrm{TiO}_{2}$. Environ. Sci. Technol. 2017;51:3973-3981.

25. Sarria V, Parra S, Invernizzi M, Perniger P, Pulagarin C. Photochemical-biological treatment of a real industrial biorecalcitrant wastewater containing 5-amino-6-methyl-2-benzimidazolone. Water Sci. Technol. 2001;44:93-101. PMID:11695489

26. Sarria V, Parra S, Adler N, Perniger P, Pulagarin C. Recent development in the coupling of photo-assisted and aerobic biological processes for the treatment of biorecalcitrant compounds. Catal. Today 2002;76:301-315.

27. Zeng Y, Hong PKA, Waverk DA. Integrated chemical-biological treatment of benzo(a)pyrene. Environ. Sci. Technol. 2000;34: 854-862.

28. Amador JA, Alexander M, Zika RG. Sequential photochemical and microbial degradation of organic molecules bound to humic acid. Appl. Environ. Microbiol. 1989;55:2843-2849.

29. Esplugas S, Contreras S, Ollis DF. Engineering aspects of the integration of chemical and biological oxidation: simple mechanistic models for the oxidation treatment. J. Environ. Eng. 2004;130:967-974.

30. Goi A, Trapido M, Tuhkanen T. A study of toxicity, biodegradability and some by-products of ozonised nitrophenols. Adv. Environ. Res. 2004;8:303-311.

31. Essam T, Aly Amin M, El Tayeb O, Mattiasson B, Guieysse B. Solar-based detoxification of Phenol and p-nitrophenol by sequential $\mathrm{TiO}_{2}$ photocatalysis and photosynthetically aerated biological treatment. Water Res. 2007;41:1697-1704.

32. Essam T, Aly Amin M, El Tayeb O, Mattiasson B, Guieysse, B. Sequential photochemical-biological degradation of chlorophenols. Chemosphere 2007;66:2201-2209.

33. Tamer E, Hamid Z, Aly AM, Ossama ET, Bo M, Bemoit G. Sequential UV biological of chlorophenols. Chemosphere 2006;63:277-284.

34. Shah MP. Combined application of Biological-photocatalytic process in Degradation of Reactive Black Dye: An Excellent Outcome. Am. J. Microbiol. Res. 2013;1:92-97.

35. Samir R, Tamer E, Yasser R, Hashem A. Enhanced photocatalytic-biological degradation of 2,4 dichlorophenoxyacetic acid. Bull. Fac. Pharm. Cario Univ. 2015;53:77-82.

36. Sharma T, Toor AP, Rajor A. Degradation of imidacloprid in liquid by enterobacter sp. strain ATA1 using co-metabolism. Biorem. J. 2014;18:227-235.

37. Sharma T. Sequential Microbial-Photocatalytic process for degradation of Neonicotinoid pesticide. [Dissertation]. Patiala; Thapar Institute of Engineering \& Technology; 2015.

38. Jafari N, Kermanshahi RK, Soudi MR, Mahavi AH, Gharavi S. Degradation of textile reactive azo dye by a combined biological-photocatalytic process: Candida tropicalis Jks2-TiO2/UV. Iran. J. Environ. Health Sci. Eng. 2012;9:33.

39. Gonzalez LF, Sarria V, Sanchez OF. Degradation of chlorophenols by sequential biological-advanced oxidative process using Trametes pubescens and $\mathrm{TiO}_{2} / \mathrm{UV}$. Bioresour. Technol. 2010;101:3493-3499.

40. Balcioglu IA, Cecen F. Treatability of kraft pulp bleaching wastewater by biochemical and photocatalytic oxidation. Water Sci. Technol. 1999;40:281-288.

41. Li XY, Zhao YG. Advanced treatment of dying wastewater for reuse. Water Sci. Technol. 1999;39:249-255.

42. Suryaman D, Hasegawa K, Kagaya S. Combined biological and photocatalytic treatment for the mineralisation of phenol in water. Chemosphere 2006;65:2502-2506.

43. Sraw A, Kaur T, Pandey Y, Sobti A, Wanchoo RK, Toor AP. Fixed bed recirculation type photocatalytic reactor with $\mathrm{TiO} 2$ immobilized clay beads for the degradation of pesticide polluted water. J. Environ. Chem. Eng.2018;6:7035-7043. 